\title{
Theorizing social innovation to address marginalization
}

\author{
Nadia von Jacobi, Alex Nicholls, Enrica Chiappero-Martinetti
}

This is an Accepted Manuscript of an article published by Taylor \& Francis in Journal of Social Entrepreneurship, 20I7, Vol.8 (3), pp: 265-270; available at https://doi.org/Io.Io80/19420676.2017.1380340

Social innovation has increasingly been referred to as a potential driver for disruptive - social change, be it in attempts to change existing systems or in the creation of entirely new solutions to pressing social needs. Across the public, private and third sectors, there has been growing attention given to innovative solutions aiming to reform social welfare. Social innovation offers the potential to provide solutions to social needs that the current institutional status quo neglects or only partially attends to. For this reason, it is not a surprise that research on social innovation and its impact has been growing recently. However, many lines of research remain including the need better to understand: the relationship between social innovation and public policy; the processes by which social innovation can alter inequalities and recast opportunities across society; how to measure the impact of social innovation.

This special issue concentrates on the empirical findings produced by the research project CrESSI (CReating Economic Space for Social Innovation). CrESSI is a fouryear research programme (2014-2018) funded by the Seventh Framework Programme of the European Community for Research, Technological Development and Demonstration Activities. The research focuses on social innovation and its potential to tackle marginalization in Europe. The CrESSI project defines 'social innovation' as:

The development and delivery of new ideas and solutions (products, services, models, markets, processes) at different socio-structural levels that intentionally seek to change power relations and improve human capabilities, as well as the processes via which these solutions are carried out (CrESSI Consortium, 2013, p. 3)

CrESSI has developed a theoretical-analytic framework - the Extended Social Grid Model (ESGM) - to explore the economic underpinnings of marginalization and social innovation in Europe. This framework takes an institutionalist perspective that draws on a range of theoretical contributions from economics, sociology and philosophy. From this framework it is possible better to understand the structural determinants of marginalization and social innovation that operate within the market and social sphere. 
The logic of the CrESSI approach suggests that in order to tackle marginalization, it is necessary to identify and address the structural processes that give rise to it. Similarly, the conditions under which social innovation flourishes or fails need fully to be understood to explore its potential as a driver of structural change. CrESSI proposes that marginalization and social innovation are shaped by the prevailing socio-economic and political system. Drawing upon prior work in economic sociology - notably that of Beckert (2010) - this process is described here as framed and shaped by a 'Social Grid' wherein co-evolutionary relationships shape the social and economic space within which marginalization (and other socio-economic phenomena) occurs. Concomitantly, these social dynamics also influence the capacity for social innovation to act as a means of redress. This Social Grid is made up of three key social forces: 'institutions', 'social networks' and 'cognitive frames' (see Figure I).

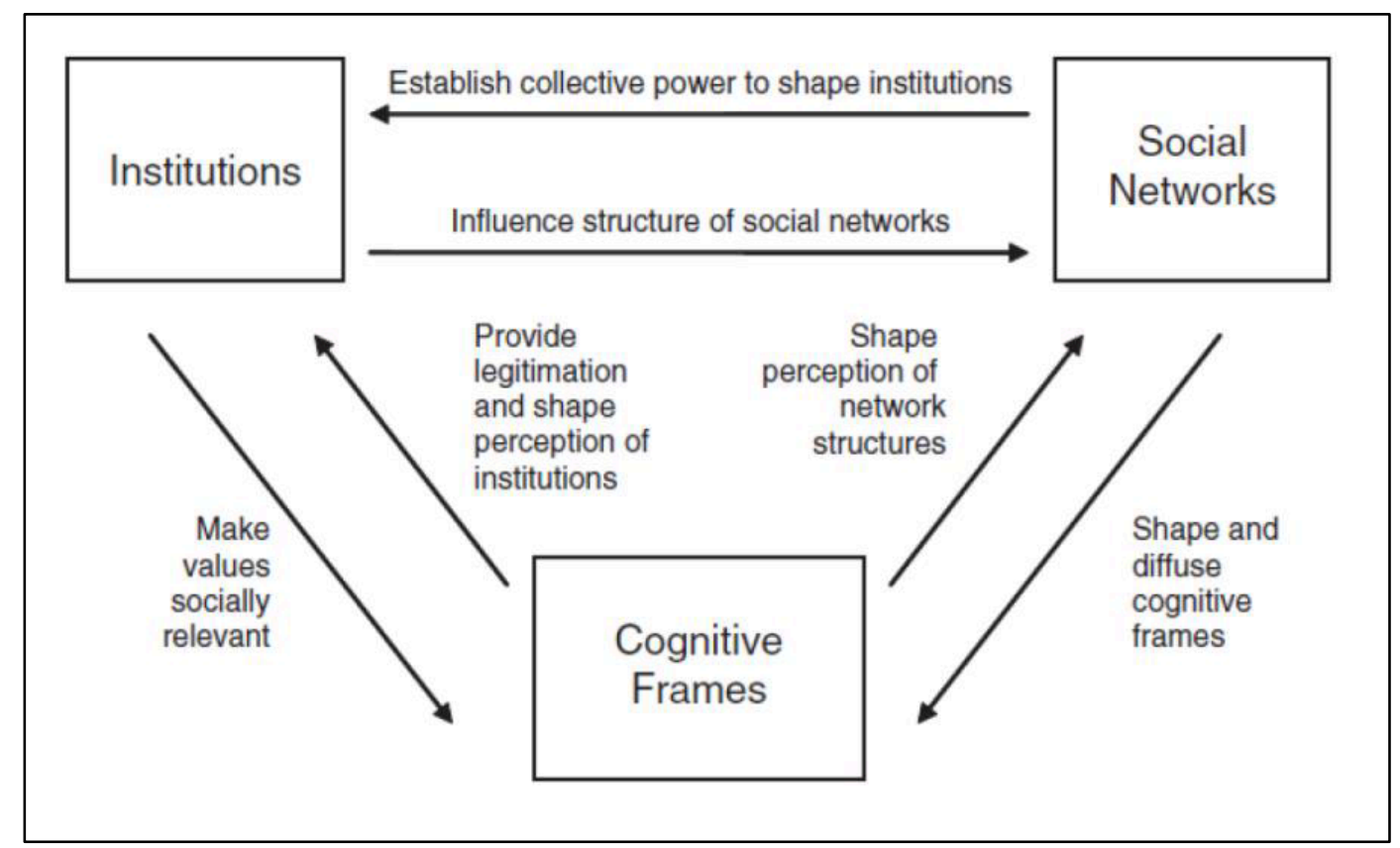

Figure I: The Social Grid (Beckert, 20I0).

According to the framework, these three social forces do not exist in isolation they operate in dialectic with one another. The social dynamics between institutions, social networks and cognitive frames will have some bearing on the prevalence and typology of marginalization within a given society, as well as on the capacity for social innovation to address this.

Building on the work of Beckert, CrESSI developed the Extended Social Grid Model (ESGM). In addition to the macro-level theorizing drawing upon Beckert, this conceptual framework also engages with two other major streams of work in the social sciences: Mann's meso-level typology of power; Sen's micro-level capabilities theory. Taken together, the ESGM suggests that processes of marginalization can be best understood as the consequence of patterns in the social grid that are articulated across various types of power in a hierarchical socio- 
economic model to affect individual flourishing. From this perspective, social innovation represents disruptions in the hierarchical model that change patterns of marginalization to allow individuals better to realize their capabilities.

Thus, the ESGM analyses both social change as well as the reproduction of marginalization and exclusion within an interrelated grid of social networks, institutions and cognitive frames. Within this theoretical framework, social innovation is located not only within economic power dynamics but also - drawing upon Mann - within the interplay of economic, political, cultural, artefactual, environmental and security-related types of social power. This perspective conceptualizes social innovation as the realignment of distributive and collective power, in a 'long view' historical context atypical of most analyses of social innovation to date..

By drawing on the work of Nussbaum and Sen, the ESGM casts marginalization in terms of constraints on human capabilities - the real opportunities to do and be what an individual has reason to value. This provides a new interpretation of social innovation in terms of a focus on the ways that people are included in (or excluded from) the formulation of their own means and ends. Marginalization is - from this perspective - not a condition inherent in specific characteristics of people, but instead the result of a social process through which personal, social or environmental traits are transformed into actual or potential factors of disadvantage (von Jacobi et al. 20I7, p. 4).

The ESGM further sensitizes us to the multi-level realities of social innovation development and implementation. From the international to the local level, institutions profoundly affect social relations and the capabilities of EU citizens. Policies, laws and regulations control the (re-) distribution of resources and services. This influences the extent to which individuals are marginalized from common experiences and opportunities available across the EU. Political, economic and social institutions reproduce rules and norms that can constrain or enhance social innovation to address these phenomena. Social networks existing between and within EU Member States determine the structure of social divisions. Patterned relations between individuals, groups and communities will dictate whether a particular social innovation is suitable, how it might work and what its effects could be. Finally, dominant attitudes (or cognitive frames) inform how socio-economic phenomena are understood and explained by the general public and policy-makers. Shared or common interpretations of societal challenges frame what solutions are conceived as possible or appropriate. For example, established ways of thinking and assumptions about the causes of poverty and social exclusion inform policy responses to marginalization and the extent to which social innovation is seen as a solution.

Therefore, marginalization and social innovation can be seen as embedded within a set of co-dependent relationships. Social innovation will inevitably have some 
bearing (positive or negative) on marginalization, but equally, marginalization shapes the capacity and character of social innovation processes. Once understood as such, analysis of social innovation takes on a novel form.

In this special issue, we present a part of the rich empirical material produced by the CrESSI research project. In the studies collected in this volume, the authors have concentrated on on-going social innovation cases in Europe. Elsewhere, the findings of long-term historical investigations of social innovation are also considered (see Scheuerle et al. 20I6; Schimpf et al. 20I7). The four cases presented in this special issue include sustainable purchasing groups in Italy - who seek to use their political consumerism in order to support small-scale, organic farmers and other disadvantaged producers such as prisoners or workers in cooperatives; communal interest groups in Germany - who engage in political activism in order to preserve local water sources, in opposition to mainstream freshwater provision networks; private money systems in the Netherlands - that actively seek to change the prevailing monetary system and to foster the local economy; an integrated microcredit programme in Hungary - which attempts to overcome the social exclusion of Roma.

The four cases are idiosyncratic and country-specific. They focus on different groups, which may be considered as "marginalized" to different degrees. In all cases, some aspects of the social process taking place in the Social Grid tend to transform personal or environmental traits into factors of disadvantage. The standard food distribution networks tend to marginalize small farmers who produce according to environmental and ethical standards in its race-to-thebottom for prices of goods. The Social Grid framing freshwater management tends to disregard local potentialities for environmental preservation in its challenge to connect all to a centralized system. The Social Grid drives norms around the perception and use of money that marginalize producers and consumers who seek values in goods and services that go beyond mere monetary thinking, such as ethical or collaborative working conditions, the conservation of traditional artisans or of local economic activities. Finally, in Hungary, the Social Grid has enshrined prejudices and cumulative processes in policy-making and institution-building have fostered the social exclusion of Roma.

By framing the analysis of these diverse cases along similar lines, e.g. from the point of view of the ESGM, this special issue seeks to contribute to the research into the transformative role that social innovation potentially plays in social systems. This is addressed in different ways by the different authors. While they all adopt an empirical approach, some (eg. van der Linden and van Beers; Ziegler) focus more on qualitative insights, while others (eg. Maestripieri, Molnár; von Jacobi and Chiappero-Martinetti) use quantitative data to estimate the effects of social innovation. Three of the cases - solidarity purchasing groups, community interest groups and systems of private money - are built upon coordinated, primary data 
collection (in a mixed method approach), which makes a comparison across cases possible (see von Jacobi and Chiappero-Martinetti in this volume). The analysis of the Hungarian case, on the other hand is based on other, secondary data, collected within the programme described.

The special issue starts with the contribution by von Jacobi and ChiapperoMartinetti, who explore how empirically to capture the multi-layered insights framed by the ESGM. This study provides insights on the methods for primary data collection and then focusses on an analysis of the data collected. The authors attempt to compare effects across solidarity purchasing groups, private capital systems and community interest groups in Italy, the Netherlands and Germany, respectively. In line with the ESGM work, their empirical analysis is centred on capturing processes through which social innovation changes society by modifying both, structural factors and individuals' agency. They propose a methodology in which effects on both individuals and societies can be measured in an integrated way. By giving more space to intangible and subjectively perceived effects, this study also sets out key issues related to the impact evaluation of social innovation. On the one hand, this contribution highlights the potential and difficulties of quantitative analysis of social innovation and, on the other, proposes a proxy measure for individual agency.

The special issue then focuses on the three above mentioned cases. In their contribution, van der Linden and van Beers provide insights on the Dutch landscape of private capital systems, which are capturing increasing attention worldwide. The authors explore which private capital can qualify as (disruptive) social innovation. They use empirical insights gathered in qualitative in-depth interviews with social innovators to identify to which extent different designs of private capital, may be able to change societies. They propose a new classification of different designs according to how capital is created and governed. By combining insights gathered in qualitative interviews with accounting analysis, van der Linden and van Beers introduce the different mechanisms by which private capital may innovate within the existing economic system. Subsequently, they discuss which of the different designs in fact classifies as social innovation in line with the theoretical framework of the ESGM. They then proceed with assessing the macroeconomic relevance of the different systems, in order to suggest which design bears greater potential for disruptiveness within society.

In her focus on the Italian case of solidarity purchasing groups, Maestripieri investigates whether social innovation can have an effect on the economic marginalization of women. Despite their growing labour market participation, many women still tend to have part-time or temporary jobs in order better to combine work and child-care activities. They can, therefore, be regarded as marginalized by a social process that tends to segregate women into certain jobs. This contribution combines insights on the structural processes that lead women in Europe to being 
marginalized within the labour market with the potential compensatory effects of social innovation processes. The ESGM elaborated in CrESSI sees social innovation as potentially able to extend the opportunities of women to be integrated into public life, to acquire an empowered position and to reduce their exposure to job fluctuations, which is often connected to financial stress and resource constraints. Italy itself is subject to the same post-industrial transformations that have changed the overall European labour force, with employment in agriculture declining at the expense of growing numbers of service jobs, a trend of increasing labour market participation among women and the effects of deregulation in the labour market increasing flexibility but also insecurity. The Italian agricultural sector - the context within which this social innovation is embedded - can be considered as an exemplary case as employment is traditionally strongly gendered in favour of men here. Maestripieri analyzes primary data collected within the CrESSI survey in order to investigate whether solidarity purchasing groups succeed in reducing the economic marginalization of women. Her work serves as contribution to the broader question of whether social innovation can reduce gender inequality and empower women in public life.

In his focus on the German case, Ziegler investigates an underexplored mode of social innovation: citizen innovation and the efforts of civil society to create something novel by seeking to restore places and practices formerly valued. In Ziegler's work, the empirical insights gathered in an in-depth case study on decentralized water management, serve as stress test for the conceptualization of citizen innovation as niche restoration. This typology can be viewed as a complement to the concept of grassroots innovation, with its particular contribution lying in the focus of the niche - a sheltered space within which citizens may be struggling against major structural developments that threaten the integrity of valued traditions or spaces. Ziegler's work has obvious implications for environmental sustainability in terms of how citizens care and fight for public goods and resources such as natural capital.

The German case explores how small and remote, rural communities entered into conflict with the extension of centralized freshwater supply and wastewater removal. The contribution creatively uses the insights gathered through qualitative interviews to stress how the novelty of social innovation was primarily associated with a critique of mainstream innovation. It also sets out how the source of social innovation does not necessarily flow out of markets, but rather results from civic action that seeks to adapt what it values in response to countervailing pressures. By combining theoretical discussion and empirical insights, Ziegler concludes with a discussion of the potential role that social innovation has to enhance the ability of citizens to enact effective participation in choice processes. He, therefore, stretches the significance of social innovation from sustainability to political philosophy, underlining its potential for political participation as a matter of contestation and control of state power exercised by vigilant citizens. 
In the final contribution to the special issue, Molnár discusses whether microfinance qualifies as social innovation. In theory, by providing access to credit to the poor, microcredit programmes offer the potential to change power structures significantly. The author concentrates on the experiences of a non-profit corporation that provided unsecured loans and mentoring primarily to the socially excluded Roma people in Hungary. Molnár's work is inspired by the capability approach developed by Sen and Nussbaum and seeks to highlight that providing loans without additional capability building was not sufficient to combat social exclusion. He uses the empirical insights gathered to underscore that only through the provision of complementary support, such as business advice, financial training, skill development, help in registering businesses and in book-keeping, can microfinance promote changes in the relative position of marginalized people and, thus, be an effective tool for empowerment.

Hungary can be considered a relatively developed transition economy representing a different European reality with respect to the other cases treated in this special issue. The Roma in Hungary (and in several other European countries) are severely disadvantaged in almost all aspects of life: education, employment, income, housing, land ownership, or health conditions. They further face discrimination because of a lack or weakness of social ties with non-marginalized social groups. As Molnár highlights, such a lack of inter-community social ties and the prejudices against the Roma mutually reinforce each other, exacerbating marginalization: as lack of knowledge due to the poor network connections increases prejudices, these prevent the establishment of connections in return. The paper describes this selffeeding, vicious circle, and uses the term 'social exclusion' to characterize such a serious form of marginalization.

The case study investigated by the author illustrates that the provision of financial and social capital together can, indeed, contribute to capability building and to the modification of the social processes that cause social exclusion. The author explores data collected through questionnaires among actual and potential clients of the programme, as well as qualitative interviews with clients and field-workers involved during the implementation. Self-assessment of clients is the key source of information as to whether capability building has taken place and whether an empowerment effect has been perceived. Molnár's investigation shows that, if microfinance is meant to alter power structures, it also requires careful design that addresses the main structural disadvantages of the poor. Failing this, it risks a mission drift towards focusing on less disadvantaged groups, whereby the exclusion of the most disadvantaged may even increase.

Overall, this special issue offers a rich set of new empirical and theoretical material with which to explore social innovation as a driver of structural, socio-hierarchical change. The cases presented here help us better understand the potentials and limitations of social innovation models in practice across a range of country contexts and from a 'long-view' historical perspective. Both these elements of 
analysis represent significant new contributions to the study of social innovation globally. It is hoped that the research presented here will seed a new wave of social innovation research across historical and cultural boundaries.

\section{References}

Beckert, J., (2010), "How Do Fields Change? The Interrelations of Institutions, Networks, and Cognition in the Dynamics of Markets" in Organization Studies 3I, pp. 605-627.

von Jacobi N., Edmiston D., and Ziegler R. (20I7), "Tackling Marginalisation Through Social Innovation? Examining the EU Social Innovation Policy Agenda from a Capabilities Perspective" in Journal of Human Development and Capabilities I8 (2), pp. I48-I62.

Scheuerle, T., Schimpf, G.-C., Glänzel, G. and Mildenberger, G. (eds.) (20I6), "Report on Relevant Actors in Historic Examples and an Empirically Driven Typology on Types of Social Innovation", CrESSI Working Paper 29/20I6.

Schimpf, G.-C. (ed.) (2017), "Comparative report on historic examples and similar recent social innovations in an early stage", CrESSI Working Paper 35/20I7. 